\section{Fortalecimento das ações de monitoramento e avaliação da atenção básica}

\section{Strengthening of monitoring and evaluation actions of the primary health care}

Ministério da Saúde. Secretaria de Atenção à Saúde. Departamento de Atenção Básica. Coordenação de Acompanhamento e Avaliação 1

${ }^{1}$ Ministério da Saúde. Secretaria de Atenção à Saúde. Departamento de Atenção Básica. Coordenação de Acompanhamento e Avaliação. Esplanada dos Ministérios, Bloco G, $6^{\circ}$ andar, sala 635. Brasília, DF, Brasil. CEP: 70.058-900. E-mail: investiga.dab@saude.gov.br Site: www.saude.gov.br/caadab

\section{Introdução}

A política de saúde do Brasil é fruto de amplo movimento da sociedade civil pela democratização da esfera pública de decisão, que se consubstancia em garantias constitucionais legitimadoras dos direitos sociais da população. Os princípios universalizantes, democráticos e participativos do Sistema Único de Saúde (SUS) se contrapõem aos modelos de atenção que privilegiam o enfoque curativo, hospitalocêntrico, verticalizado, fragmentado, tecnicista, ineficiente e pouco resolutivo. A efetiva implementação das diretrizes do SUS se configura como uma ampla possibilidade de mudança na forma como os serviços e práticas de saúde se organizam, redirecionando enfoques e ações pautados no paradigma da vigilância da saúde e na ampliação da cidadania brasileira.

A reorganização da atenção à saúde no Brasil, com fortes características do modelo médico assistencial privatista ainda presentes, requer um acúmulo de forças sociais capazes de reestruturar a produção de serviços, saberes e práticas, submetendo-as ao bem comum. Sem perder de vista a complexidade que essa discussão envolve, cabe ressaltar aqui duas premissas inadiáveis. Primeiro, no âmbito da sociedade urge fortalecer o exercício do controle social sobre as ações governamentais. Segundo, e diretamente relacionada à primeira, no escopo da gestão pública é preciso priorizar a oferta dos serviços a partir da organização da demanda. É neste aspecto que o Programa Saúde da Família (PSF) ganha relevância, sendo concebido como eixo estruturante para reorganização da atenção básica, com repercussões reordenadoras para todo sistema de saúde.
Assumido pelo Ministério da Saúde como estratégia prioritária para organização dos serviços de atenção básica, o Programa Saúde da Família vem sendo aprimorado e expandido desde sua criação, em 1994. Em setembro de 2004, são 21.475 equipes de saúde da família (ESF), distribuídas em 4.785 $(86,1 \%)$ municípios, alcançando uma cobertura de $39,4 \%$ da população brasileira.

Visando expandir a cobertura do PSF para municípios acima de 100.000 habitantes, consolidandoo como proposta reorientadora dos serviços de atenção básica do SUS, o governo brasileiro firmou acordo de empréstimo internacional com o Banco Mundial, viabilizando o início do Projeto de Expansão e Consolidação do Saúde da Família (PROESF), em 2003. Assim, até 2008 pretende-se ampliar a cobertura do PSF para $70 \%$ da população brasileira, desenvolvendo os sistemas de referência e contrareferência do SUS e aprimorando o gerenciamento dos serviços de atenção básica. Estruturado em três componentes: I - Conversão e Expansão Municipal do PSF; II) Desenvolvimento de Recursos Humanos do PSF e III) Monitoramento e Avaliação), o PROESF pode vir a se concretizar num instrumento importante para ampliar o acesso da população aos serviços de saúde, organizando-os e qualificando-os a partir da atenção básica.

Cabe à Coordenação de Acompanhamento e Avaliação da Atenção Básica do Departamento de Atenção Básica (DAB) da Secretaria de Atenção à Saúde (SAS) o desenvolvimento do Componente III do PROESF. O fortalecimento de sistemas de monitoramento e avaliação da atenção básica efetivos, principalmente nos municípios participantes do 
PROESF pautado na institucionalização das ações avaliativas, constitui um dos objetivos a serem implementados. Visa-se sobretudo incorporar os processos avaliativos no cotidiano das organizações e serviços de saúde, concebendo-os como instrumento de gestão do SUS.

Por meio do financiamento de ações previstas pelo Componente III do PROESF, e tendo por imagem-objetivo a institucionalização da avaliação da atenção básica, pretende-se fortalecer o papel das Secretarias Estaduais de Saúde (SES) no que se refere à avaliação da atenção básica, desenvolvendo as capacidades técnicas e operativas das SES. O intento maior é priorizar as atribuições de formulação, planejamento, coordenação, controle e avaliação da gestão estadual como importante estratégia para o aprimoramento da eficácia do SUS, tendo por suposto seus princípios e diretrizes. 1

Neste sentido, o presente documento estabelece concepções, diretrizes e critérios técnicos para que as SES elaborem seus Planos Estaduais para o Fortalecimento das Ações de Monitoramento e Avaliação da Atenção Básica, a serem financiados pelo Ministério da Saúde como parte das ações do PROESF. Cabe considerar os citados "Planos" como parte integrante do Plano de Saúde do Estado, uma vez que se pretende investir no potencial estruturante da avaliação no âmbito do SUS. Aqui são estabelecidos alguns pressupostos conceituais e metodológicos sobre monitoramento e avaliação da atenção básica. Fundamentados nesses preceitos, os tópicos seguintes descrevem estratégias para o fortalecimento das ações estaduais de monitoramento e avaliação, concebendo os referidos Planos Estaduais como instrumentos de gestão.

\section{Objetivos}

Estabelecer pressupostos conceituais, diretrizes e critérios técnicos para o financiamento das Ações Estaduais de Monitoramento e Avaliação da Atenção Básica;

Subsidiar a elaboração, pelas Secretarias Estaduais de Saúde, dos Planos Estaduais para Fortalecimento das Ações de Monitoramento e Avaliação da Atenção Básica;

Definir indicadores para orientar a elaboração/ execução dos Planos Estaduais de Monitoramento e Avaliação da Atenção Básica a serem financiados pelo Componente III do PROESF.

\section{Monitoramento e avaliação da atenção básica: pressupostos conceituais e metodológicos}

\section{Avaliação da atenção básica}

A avaliação em saúde pode se configurar num instrumento central para implementação da universalidade e eqüidade dos serviços de saúde, principalmente se aquilatada com a participação da sociedade no controle das ações governamentais. Refletir sobre a efetividade e eficácia das ações e serviços de saúde, supondo participação e controle democrático, pode se traduzir na ampliação do acesso à saúde da população, principalmente se tal prática se insere no cotidiano institucional das instâncias gestoras do SUS.

$\mathrm{O}$ ato de avaliar, mesmo se caracterizando como uma apreciação ou interpretação que envolve poder, pode ser construído coletivamente, assentado em compromissos públicos pactuados dinamicamente. Assim, a participação ativa de estados, municípios e usuários em momentos avaliativos, além de democratizar relações de poderes, propicia compromissos que podem viabilizar mudanças, uma vez que as responsabilidades passam a ser partilhadas na esfera pública de decisões.

Nesses termos, as instâncias de discussão e negociações do SUS, consubstanciados nas Comissões Intergestoras Bipartites e Tripartites, vêm se caracterizando como o cenário adequado para as pactuações referentes à política de saúde do Brasil. A intenção aqui assumida é a de aprimorar, de forma permanente e processual, os espaços de gestão democrática do SUS, fortalecendo a avaliação no âmbito da Atenção Básica.

A concepção de Atenção Básica pauta-se na integralidade das ações de promoção, diagnóstico, tratamento e reabilitação à saúde, assumindo um importante papel na organização do sistema de saúde do Brasil. Desenvolve-se por meio de processos de trabalho em equipe interdisciplinares, democráticos e participativos, com utilização de tecnologias de alta complexidade e baixa densidade. Seu objeto de trabalho é considerado na dimensão coletiva e na singularidade do sujeito, tendo por finalidade a resolubilidade dos problemas de saúde da população mais freqüentes e relevantes.

Avaliar a atenção em saúde é um processo complexo que envolve compreensão de conjuntura apurada e percepção crítica de como as práticas e 
serviços de saúde se inserem no contexto que se pretende analisar. Entender a avaliação como "complexa" não significa necessariamente dizer que seja complicada, 2 uma vez que a finalidade maior das técnicas e instrumentos empregados no processo de avaliação é tentar realizar sínteses que direcionem ações e proposições.

Mesmo a avaliação sendo desenvolvida na esfera da burocracia pública e não propriamente no ambiente acadêmico, a discussão sobre concepção de realidade é pertinente, uma vez que direciona práticas, métodos, abordagens, argumentações e conclusões. Afinal, teoria e prática são parte de um mesmo fenômeno, não sendo mais possível sustentar dicotomias ou paradigmas cartesianos que se contraponham aos princípios do SUS.

A compreensão da atenção básica em saúde como processo complexo, inserido numa realidade social dinâmica, não-linear, permeada por contrários e correlações de forças, influencia concepções e proposições avaliativas. Assim considerado, entende-se que a avaliação é um procedimento crítico-reflexivo, contínuo e sistemático desenvolvido sobre as práticas e processos de trabalho dos serviços de saúde. Como formalização, capta parcialmente a realidade, uma vez que, sendo método, afere apenas o que se explicita com maior frequiência e relevância interpretativa no contexto estudado.

Outro ponto a se considerar é que o foco da avaliação, ou objeto, é sempre "construído" ou "delimitado" pelos sujeitos envolvidos no ato de avaliar. Ou seja, os "fatos" não estão dados ou "evidentes" na natureza, mas são delimitados a partir de distintas interpretações da realidade. Acredita-se que esta objetivação da realidade, por mais metodologicamente fundamentada que esteja, sempre será um recorte, jamais o todo.

Assumindo tais pressupostos como referência epistemológica, poder-se-ia conceituar avaliação como um processo participativo de interpretação parcial de cenários pré-delimitados (ou construídos) - inserido numa realidade complexa, não-linear, permeada por relações de poder e fundamentado em sistematizações formais de análise - que visa explicitar situações para orientar ações e intervenções críticas no contexto sócio-histórico.

Longe de quaisquer dicotomias mais restritivas, cabe considerar o monitoramento como face dialética complementar aos processos avaliativos. A avaliação de cenários e perspectivas em saúde pressupõe a constante vigilância e acompanhamento de seus indicadores, traduzindo-se em ações rotineiras, planejadas e sistematizadas a partir da realidade que se pretende analisar para modificar. Nesses termos, é preciso monitorar cotidianamente as situações para melhor avaliá-las na amplitude requerida, entendendo tal monitoramento como parte e momento dinâmico das próprias ações avaliativas em curso.

\section{Abordagens metodológicas: diretrizes}

Inserir a participação no contexto da avaliação pressupõe processualidade permanente e constante refinamento dos instrumentos, meios e técnicas utilizados. Entender sujeito e objeto como partícipes do mesmo processo social, dinâmico e ambivalente, exige abordagens em avaliação que contemplem suas limitações frente aos cotidianos sociais. Isso significa o aperfeiçoamento constante dos instrumentos formais de análise, na tentativa de aproximar-se qualitativamente dos fenômenos estudados. Importante ratificar que, ao se recortar uma realidade, na tentativa de melhor compreendê-la, não se pode esquecer o todo a que ela faz parte. Tal assertiva pressupõe aproximar-se do fenômeno estudado, descobrir-lhe sentidos e relações, sugerir-lhe inovações críticas, porém prevendo sempre sua transitoriedade e superação.

Visto dessa forma, as abordagens metodológicas a serem empregadas primam pela integralidade e pluralidade de interpretações, no sentido de ampliar os focos de análises e as possibilidades de resultados. Tal concepção metodológica permitiria, por exemplo, dimensionar questões norteadoras de avaliação da atenção básica para além de seus componentes mais facilmente quantificáveis, tratando o alcance das metas nas dimensões subjetivas e contextuais, melhor analisadas por abordagens qualitativas.

A abordagem qualitativa da avaliação não nega a quantidade enquanto componente dialeticamente complementar. Qualidade e quantidade co-existem nos fatos sociais como unidade de contrários, superáveis e aperfeiçoáveis ao mesmo tempo. Assim, enfoques quantitativos e qualitativos podem ser desenvolvidos juntos, uma vez que compõem uma mesma realidade a ser esmiuçada.

Propõe-se, pois, que elementos quantitativos e qualitativos permeiem as ações estaduais de avaliação da atenção básica. Nesse sentido, haverá momentos em que o dado quantitativo poderá ser mais priorizado, principalmente quando se pretende descrever ou diagnosticar perfis e cenários. Noutros, quando se pretender desconstruir/reconstruir causas e desvelar superficialidades, será a dimensão subjetiva que se procurará analisar mais, numa tentativa de desvelar aspectos subjacentes ao dado objetivamente colhido. Significa dizer que os instrumentos, indicadores, meios e técnicas de avaliação empregados, 
sempre a serviço da realidade que se pretende refletir, estarão em constante reconstrução e adequação para melhor apreensão de informações que subsidiem a análise.

\section{Dimensões de análises}

As dimensões de análises auxiliam numa melhor estruturação dos diversos aspectos a serem enfocados na avaliação, dando maior visibilidade ao que se pretende captar. São recortes possíveis e incompletos de um contexto sempre mais rico e imprevisível, como o são as relações sociais. Seja qual for o recorte ou opção metodológica adotada para avaliação da atenção básica, essa deve ser pensada de forma integrada, articulando o contexto em que as práticas ocorrem, as correlações de forças aí existentes e as produções sociais realizadas.

Uma possibilidade de desenho a ser adotado a partir dessa discussão poderia prever três dimensões: a) político-insitucional; b) organizacional e c) atenção à saúde. A primeira, político-institucional, procura visualizar o contexto da política pública, focando-se nos vários aspectos relacionados à gestão do SUS. A segunda, organizacional, refere-se à organização dos serviços e práticas de saúde. A terceira, atenção à saúde, insere-se no cotidiano das práticas de promoção, prevenção e recuperação ou reabilitação da saúde desenvolvidas, tendo como foco a atuação dos profissionais de saúde. Numa tentativa de sinalizar outras possibilidades de análises a serem adotadas a partir desta discussão, recomendam-se as seguintes diretrizes:

Elaborar dimensões concebidas de maneira articulada e processual, embora com especificidades bem delimitadas e calcadas nos princípios do SUS;

Prever recortes que contemplem o contexto em que a atenção básica à saúde se insere, bem como as relações sociais e institucionais nele presentes, como parte de uma mesma dinâmica produtora de serviços, práticas e subjetividades;

Construir dimensões que possibilitem o desenvolvimento de avaliações quantitativas e qualitativas, entendendo-as complementares.

\section{Indicadores de avaliação}

Tendo em vista a dinâmica das dimensões aqui consideradas, os princípios e diretrizes do SUS, bem como a necessidade de analisar o impacto da organização da atenção básica sobre os indicadores de saúde da população, considerem-se como referências centrais prioritárias para a definição do corpo de indicadores a serem incorporados nos Planos Estaduais:
Os objetivos, metas e produtos previstos no item 4.2 Os indicadores previstos para acompanhamento dos municípios participantes do PROESF;

Os indicadores do Sistema de Informação da Atenção Básica e do Pacto da Atenção Básica de 2003;

As atribuições das SES previstas no item 4.4.

$\mathrm{Na}$ medida em que os contextos forem se modificando, principalmente com a participação dos diversos atores envolvidos, alguns dos indicadores priorizados pelas SES poderão se modificar ou serem acrescidos de outros, advindos das especificidades e realidades locais.

\section{Planos estaduais para fortalecimento das ações de monitoramento e avaliação da atenção básica}

\section{Planos estaduais: concepção,} linhas norteadoras e macroestratégias

As propostas das Secretarias Estaduais de Saúde para fortalecimento das ações de monitoramento e avaliação da atenção básica a serem financiadas pelo Componente III do PROESF seguirão os pressupostos estabelecidos neste documento, conformando-se num plano enquanto desenho macroestratégico pretendido. Os Planos Estaduais constituem um instrumento importante para a implementação dos processos avaliativos em andamento nas SES, prevendo diretrizes, objetivos, estratégias e operações voltadas para melhor estruturação das atividades desenvolvidas. Em síntese, é a descrição da situação atual, seus problemas, fatores causais, desenho de ações e estratégias para implementar a avaliação da atenção básica no estado.

O intento maior a ser perseguido pelas SES, neste caso, será o de potencializar ações, projetos, programas, áreas técnica, pessoal e recursos financeiros já existentes, articulando-os num processo de trabalho convergente em objetivos e metas. Nesse sentido, cabe prioritariamente aos estados uma análise dos processos avaliativos da atenção básica existente na SES, destacando entraves e perspectivas, com o objetivo de delinear prioridades e estratégias para superação do cenário descrito.

Os Planos Estaduais precisam ser entendidos como uma ferramenta de planejamento e gestão elaborados de maneira integrada, flexível e adaptável às mudanças requeridas pela realidade, cujo compromisso maior pauta-se na institucionalização da avaliação da atenção básica. Tal concepção pretende fortalecer a incorporação dos processos avaliativos 
no cotidiano de práticas, regras e cultura organizacional das secretarias de saúde. Institucionalizar significaria, então, fazer parte, compor intrinsecamente, internalizar padrões e produzir comportamentos socialmente estabelecidos. Nesses termos, talvez fosse o caso da institucionalização ser compreendida também como socialização, no sentido descrito por Outhwaite e Bottomore, ${ }^{2}$ entendida como processo pelo qual as pessoas são induzidas a adotar padrões de comportamento, normas, regras e valores do seu mundo social.

A institucionalização da avaliação da atenção básica nas SES fundamenta-se na responsabilidade da gestão estadual quanto à formulação da política e nas atribuições de planejamento, de co-financiamento, de qualificação dos processos de trabalho em consonância com os princípios do SUS e de cooperação técnica aos municípios. Dessa forma, se vislumbra impulsionar maior sistematização, coordenação e integração nas atividades gestoras desenvolvidas, buscando-se aprimorar a eficácia das ações e a efetividade dos serviços de atenção básica do SUS.

Assim, e considerando a necessidade de se imprimir maior organicidade institucional aos processos de avaliação da atenção básica desenvolvidos pelas SES, espera-se que os Planos Estaduais a serem elaborados estejam pautados nas seguintes linhas norteadoras:

I. Entendimento do Programa Saúde da Família como estratégia prioritária para a organização das práticas e serviços de atenção básica, repercutindo na gestão do sistema de saúde;

II. O fortalecimento das ações de avaliação da atenção básica pauta-se na integração dos distintos processos de trabalho da SES, o que significa, minimamente, a articulação efetiva com as áreas previstas na NOAS 01/02, bem como com os setores de regulação e programação;

III. Para maior integração das ações desenvolvidas, recomenda-se que sejam previstas estratégias institucionais para uma maior articulação entre as áreas de Atenção Básica, Planejamento, Epidemiologia, Informação em Saúde e Vigilâncias (epidemiológica, ambiental e sanitária) no processo de formulação e implementação da avaliação da atenção básica, no âmbito do estado;

IV. As ações integradas de avaliação da atenção básica se subordinam, preferencialmente, a área, coordenação, departamento e/ou estrutura organizacional da SES responsável pela gestão da atenção básica no estado, onde também está inserida a condução da estratégia saúde da família;

V. A avaliação da atenção básica é concebida como um instrumento democrático de gestão do sis- tema de saúde constante no Plano Estadual de Saúde aprovado pelo CES e pactuado na Comissão Intergestoras Bipartites (CIB), pressupondo a integração dos sistemas de informação, pactos e programações em saúde como principais ferramentas gerenciais;

VI. Prioridade no fortalecimento da infra-estrutura física, de equipamentos e pessoal das SES, em nível central e nas regionais de saúde, como forma de potencializar a capacidade executora de processos avaliativos da atenção básica.

\section{Macroestratégias}

Os Planos Estaduais para fortalecimento das ações de monitoramento e avaliação da atenção básica, devem prever pelo menos três momentos ou fases de execução macroestratégicas, que se articulam e reconstroem-se dinamicamente. O primeiro, denominado "desenvolvimento da capacidade técnica", visa aprimorar sistematicamente os processos de trabalho dos profissionais envolvidos na proposta de avaliação da atenção básica, portanto realizar-se-á durante todo o desenvolvimento das ações. O segundo, avaliação pactuada da atenção básica, objetiva desencadear processos de responsabilização partilhada sobre a avaliação da atenção básica, envolvendo estado e municípios nas análises e pactuações realizadas. O terceiro, análise do fortalecimento das ações estaduais de monitoramento e avaliação, objetiva verificar a eficácia do Plano, à luz da efetividade das ações desenvolvidas. Esta etapa, que subsidia as demais, constitui uma oportunidade para redirecionar estratégias, objetivos e metas, dinamizando a avaliação tanto em relação aos municípios, quanto em relação ao estado e Ministério da Saúde.

\section{A - Momento inicial (MI): desenvolvimento da capacidade técnica}

O fortalecimento da capacidade técnica das SES constitui um aspecto central para operacionalização dos Planos Estaduais. Embora prevista formalmente nessa primeira etapa, a qualificação dos profissionais é parte intrínseca ao desenvolvimento das ações avaliativas. $\mathrm{O}$ desenvolvimento da capacidade técnica poderia ser visto como processo permanente de aprendizado institucional, portanto calcado em avaliações formativas, modificadoras de práticas e cenários.

Para a execução dessa primeira fase, as secretarias estaduais contariam com a parceria de instituições de ensino e pesquisa de excelência na área de avaliação em saúde e afins. Tais instituições, a serem contratadas pelas SES, se constituiriam em Centros 
Colaboradores em Avaliação da Atenção Básica, sendo co-responsáveis pelo aprimoramento e qualificação dos processos de trabalho dos profissionais.

Concomitante a esse processo de fortalecimento da equipe técnica da SES, os Centros Colaboradores em Avaliação da Atenção Básica deverão assessorar a elaboração da proposta metodológica para monitoramento e avaliação da atenção básica a ser desenvolvida no estado. Assim, o principal produto a ser trabalhado pela equipe da SES e Centros Colaboradores durante esta fase seria a construção (ou aprimoramento) dos métodos e instrumentos a serem utilizados na avaliação da atenção básica no âmbito do estado, tendo por referência a realidade local e as diretrizes pactuadas.

\section{B - Momento de desenvolvimento (MD): avaliação pactuada da atenção básica}

Concluída a proposta metodológica para o monitoramento e avaliação da atenção básica pelas SES, assessorado pelos Centros Colaboradores e primeiro produto constante nos Planos Estaduais, passa-se à execução das propostas. Para tanto, faz-se necessário dinamizar os vários instrumentos de avaliação da atenção básica (Pacto de Indicadores, Sistema de Informação da Atenção Básica, demais sistemas de informação, outros) utilizando-os como ferramentas de gestão articuladas à programação e acompanhamento das ações. A avaliação que se deseja fortalecer, pois, estaria pautada em processos mais participativos e democráticos, onde as dimensões política e técnica das parametrizações realizadas ganham relevo e intensidade.

A partir desse entendimento, estado e municípios assumiriam metas e indicadores como mecanismos eficazes de responsabilização partilhada, constituindo-se nos principais produtos desta etapa, com definição de compromissos e atribuições a serem cumpridos em prazos determinados. Embora o processo de pactuação seja um dos fundamentos essenciais na gestão do SUS, tal processo tem se constituído como expediente burocrático e cartorial em muitos aspectos, inclusive nas ações avaliativas desenvolvidas. Trata-se, pois, de dinamizar e renovar processos já existentes, pressupondo-os centrais para a democratização na gestão pública de saúde.

\section{C - Momento processual-finalístico (MPF): análise do fortalecimento das ações estaduais de monitoramento e avaliação}

O fortalecimento das ações estaduais de monitoramento e avaliação da atenção básica pressupõe um aperfeiçoamento sistemático, crescente, integrado e contínuo dos processos de trabalhos nas SES. Nesse sentido, o momento processual finalístico dos Planos Estaduais visa oportunizar processos de avaliação interno nas secretarias estaduais, onde tanto a eficácia do Plano, quanto as práticas desenvolvidas e cenários modificados se constituiriam em objeto de análise. É um momento para viabilizar a avaliação das metas e ações previstas no Plano, redirecionando-as e aprimorando-as.

Entendida como processual, essa fase estaria presente nos vários momentos da execução do Plano, conformando-se em produtos e resultados parciais do trabalho desenvolvido. Ao final do momento inicial, e em diversos marcos da fase de desenvolvimento, as secretarias estaduais realizariam uma avaliação institucional com o intento de melhor dimensionar e/ou estruturar o fortalecimento das ações previstas. Concebido também como finalístico, este momento corresponde ao cumprimento de metas pactuadas com o Ministério da Saúde, constantes da carta de compromissos assinada por ocasião da aprovação dos Planos, estando atrelado ao monitoramento a ser realizado pelo DAB/SAS e ao repasse das parcelas correspondentes ao financiamento.

O momento processual-finalístico (MPF) deve prever indicadores de avaliação de acordo com os objetivos e metas traçadas no Plano, que por sua vez se respaldam na concepção, linhas norteadoras e diretrizes metodológicas. Entenda-se que esses momentos avaliativos devem fazer parte do próprio cotidiano de execução dos Planos, não necessitando de maiores formalidades para sua realização, uma vez que se deseja institucionalizar a avaliação cotidianamente. Saliente-se, ainda, que o acompanhamento dos Planos Estaduais aprovados, a ser realizado pelo DAB/SAS utilizarão também as informações, produtos e resultados relatados nessas fases de análises pontuais. Assim, sistematicamente os estados serão avaliados no cumprimento das metas por meio, principalmente, dos MPF previstos e realizados.

Em linhas gerais, e tentando estruturar a idéia de complementaridade, não-linearidade e integralidade entre os três momentos do Plano Estadual, têm-se o esquema (Figura 1) a seguir: 


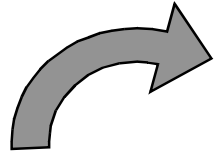

Momento processual-finalístico (MPF): Análise do fortalecimento das ações de monitoramento e avaliação

\section{Momento inicial (MI): Desenvolvimento de capacidade técnica}

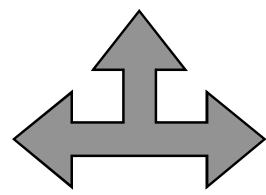

Momento de desenvolvimento (MD):

Avaliação pactuada da atenção básica

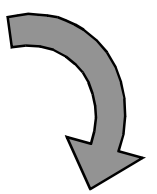

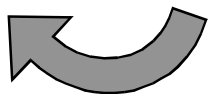

\section{Dos planos iniciais à elaboração e realização da proposta metodológica para monitoramento e avaliação da atenção básica}

Para contemplar as macroestratégias aqui desenhadas, as SES formularão seus Planos em dois tempos. No primeiro, o Plano Estadual-1 e denominado Plano inicial, a ser apresentado ao DAB/SAS, objetiva delinear a intenção do estado para a institucionalização da avaliação atenção básica, contemplando estratégias e ações para o Momento inicial (MI) acima descrito. Após a realização do Momento inicial, e como produto dele, as SES apresentam seus Planos Estaduais-2, "Proposta Metodológica para Monitoramento e Avaliação da Atenção Básica", constuindose no seguimento ao primeiro Plano inicial apresentado. Assim, a primeira parcela do recurso será repassada após análise do Plano Estadual-1 e financiará o desenvolvimento do momento inicial. Já a segunda parcela será repassada mediante a análise das Propostas Metodológicas apresentadas (Plano Estadual-2), iniciando-se então o segundo momento, onde será executada a proposta desenhada. Os planos estaduais subsequentes correspondem aos relatórios de desenvolvimento dos momentos processuais-finalísticos, com a análise das respectivas metas, indicadores e produtos previstos. Definindo melhor, têm-se:

I. Plano Estadual-1. Plano inicial: primeira manifestação de interesse das SES para receber o financiamento do PROESF. Minimamente, deve conter os seguintes itens: a) descrição da situação de ABS no estado; b) dimensionamento de pessoal que participará do momento inicial - desenvolvimento de capacidade técnica; c) previsão de realização do primeiro MPF; d) critérios para contratação dos centros colaboradores; e) custos e investimentos;

II. Plano Estadual-2. Proposta metodológica para monitoramento e Avaliação da Atenção Básica: produto do desenvolvimento da capacidade técnica (Momento inicial) realizado pelas SES e assessorado pelos centros colaboradores em Avaliação da Atenção Básica. Refere-se ao desenho estratégico e metodológico da SES para o fortalecimento das ações de monitoramento e avaliação da atenção básica. Contempla os métodos, abordagens, ações prioritárias, atividades, metas, indicadores e instrumentos que serão utilizados, além dos custos e investimentos pensados para melhor estruturação das ações de monitoramento e avaliação da atenção básica (M\&A da $A B)$ na SES. 


\section{Objetivos, metas e produtos esperados das SES}

\section{Quadro 1}

Momento inicial (MI). Desenvolvimento de capacidade técnica (seis primeiros meses após a assinatura da "Carta de compromisso".

Objetivos
(Re)Estruturar equipe de trabalho que desenvolverá as atividades de monitoramento e avaliação no estado;

Fortalecer os processos de trabalho e o desenvolvimento da capacidade técnica da equipe, com assessoria dos Centros Colaboradores em Atenção Básica;

(Re)Elaborar, com assessoria dos Centros Colaboradores em Avaliação da atenção Básica, Proposta Metodológica para Monitoramento e Avaliação da Atenção Básica do estado;

Realizar um momento processual-finalístico (MPF) pautado em avaliações formativas interna e externamente à SES

Metas

1. Expandir/(re)estruturar número de profissionais da SES envolvidos com as ações de monitoramento e avaliação da atenção básica (M\&A da $A B$ ) em nível central e em 100\% das regionais de saúde;

2. Iniciar aperfeiçoamento/fortalecimento da estrutura física e de equipamentos da SES para o desenvolvimento das ações estaduais de fortalecimento do M\&A da $A B$;

3. Desencadear ações voltadas para a integração entre as distintas áreas, instrumentos e processos de trabalhos ligados ao M\&A na SES, elaborando documento em que sejam demarcadas as atribuições, objetivos, meta e estratégias a serem aperfeiçoados;

4. Assessorar os municípios na atualização do Cadastro Nacional dos Estabelecimentos dos serviços de Saúde

5. Realizar capacitação inicial com $100 \%$ dos profissionais da equipe de $M \& A$ da $A B$ no estado, com a assessoria dos Centros Colaboradores em Avaliação da Atenção Básica contratados;

6. Apresentar, discutir e aprovar a Proposta Metodológica para Monitoramento e Avaliação da Atenção Básica na Comissão Intergestores Bipartite e Conselho Estadual de Saúde.
Produtos

1. Equipe de Avaliadores dimensionada e conformada em nível central e nas regionais de saúde;

2. Ampliação da Infra-estrutura física e de equipamentos da SES iniciada;

3. Documento norteador para integração dos processos de M\&A da SES contendo meta, objetivos, estratégias e atribuições elaborado;

4. Cadastro Nacional dos Estabelecimentos dos Serviços de Saúde atualizado;

5. Centros Colaboradores contratados. Equipe preliminarmente capacitada. Avaliações formativas realizadas (Momento Processual-Finalístico);

6. Proposta metodológica para monitoramento e avaliação da atenção básica apresentada, com especificação de estratégias diferenciadas para municípios participantes ou não do PROESF. Ata da CIB e CES. 
Momento de desenvolvimento (MD).

Objetivos

Executar as ações previstas na Proposta Metodológica Para Monitoramento e Avaliação da Atenção Básica aprovada pelo DAB/MS

Realizar um momento processual-finalístico (MPF) pautado em avaliações formativas interna e externamente à SES.

Metas

1. Fortalecer a infra-estrutura física, de equipamentos e de capital da SES para o desenvolvimento das atividades de M\&A da $A B$, de acordo com Plano Estadual aprovado pelo $\mathrm{DAB} / \mathrm{MS}$;

2. Implementar ações voltadas para a integração entre as distintas áreas, instrumentos e processos de trabalhos ligadas ao M\&A na SES, avaliando os objetivos, metas e produtos;

3. Executar as ações previstas na Proposta Metodológica para Monitoramento e Avaliação da Atenção Básica aprovada pela CIB, CES e DAB/MS em municípios acima e abaixo de 100.000hab, assessorando a elaboração de 2 propostas de M\&A da $A B$ em 2 municípios participantes do PROESF;

4. Monitorar e avaliar, junto aos municípios, as estratégias traçadas para o alcance das metas compromissadas no Pacto dos Indicadores da Atenção Básica de 2003, negociando e reprogramando ações em conjunto;

5. Cooperar com o município para o fortalecimento do uso do SIAB como instrumento de planejamento em nível local, traçando estratégias conjuntas a partir da discussão dos relatórios gerados por este sistema de informação;

6. Oportunizar a realização de cursos de atualização e/ou especialização na área gestão, planejamento e avaliação em saúde para a $100 \%$ da equipe envolvida com as ações de M\&A da $A B$, com a assessoria dos Centros Colaboradores em Avaliação da Atenção Básica contratados;

7. Elaborar proposta de educação permanente em saúde à equipe técnica da SES, com foco em assuntos relacionados ao monitoramento e avaliação.
Produtos

1. Infra-estrutura física, de equipamentos e de capital da SES ampliada conforme Plano Inicial;

2. Avaliação Processual-Finalística com foco na integração entre as ações realizada;

3. Apresentação de duas propostas preliminares de Monitoramento e Avaliação da Atenção Básica de municípios do PROESF, construída pelo município, assessorado pela SES e Centro Colaborador;

4. Análises da situação da atenção básica nos municípios previstos para o período;

5. Ata da Comissão Intergestoras Bipartites (CIB) com os resultados das pactuações referentes à monitoramento e avaliação da atenção básica realizadas com os municípios;

6. Ata de aprovação do CES da Proposta Metodológica para Monitoramento e Avaliação da Atenção Básica;

7. Análise das estratégias utilizadas junto aos municípios para o fortalecimento do uso do SIAB como instrumento de planejamento e gestão;

8. Equipe da SES envolvida com $M \& A$ da $A B$ matriculada em cursos de atualização e/ou especialização na área de gestão, planejamento e avaliação em saúde;

9. Proposta de educação permanente em saúde para equipe técnica da SES elaborada. 
Centros colaboradores em Avaliação da Atenção Básica: referência especializada e apoio técnico às SES

Os Centros Colaboradores para Avaliação da Atenção Básica são instituições de ensino e pesquisa (IEP), a serem contratadas pelas SES, para assessorá-las no fortalecimento da capacidade técnica e operacional do corpo de servidores e profissionais, tendo em vista a implementação das ações de monitoramento e avaliação da atenção básica propostas. Tais instituições serão responsáveis pelo suporte conceitual e metodológico necessário ao desenvolvimento das estratégias traçadas no Plano Estadual, estando voltadas ao apoio técnico e consultivo às SES. Neste sentido, os seguintes critérios para a contratação dos Centros Colaboradores devem ser considerados:

I. Instituições de reconhecida experiência em pesquisa, com produções intelectual e institucional assentadas em linhas de investigação, projetos e programas de ensino relacionados com o campo da avaliação em saúde ou áreas afins;

II. Conter equipe de pesquisa interdisciplinar com experiência na realização de estudos de avaliação em saúde ou áreas afins;

III. Apresentar proposta de trabalho em consonância com os pressupostos estabelecidos pelas SES, indicando os mecanismos de articulação interinstitucional e estratégias a serem utilizados para o desenvolvimento das ações de cooperação técnica.

Tendo por referência os critérios acima elencados, os Centros Colaboradores para Avaliação da Atenção Básica têm as seguintes atribuições:

a. Contribuir para o fortalecimento da capacidade técnica das equipes da SES envolvidas com a avaliação da atenção básica, por meio de métodos e técnicas pedagógicas centradas na qualificação dos processos de trabalho;

b. Colaborar no desenvolvimento da autonomia técnica do corpo de servidores da SES em relação à avaliação em saúde, propiciando o envolvimento das equipes de saúde municipais nos processos de capacitação desenvolvidos;

c. Assessorar a SES na implementação dos Planos Estaduais para o Fortalecimento das Ações de Monitoramento e Avaliação da Atenção Básica, colaborando tecnicamente;

d. Assessorar a SES na elaboração da proposta metodológica e operacional para o fortalecimento das ações de monitoramento e avaliação da atenção básica previsto nos Planos Estaduais, com envolvimento das equipes técnicas responsáveis pelas ações;

e. Subsidiar as gerências/coordenações de
Atenção Básica das SES no planejamento e desenvolvimento das ações de monitoramento e avaliação;

f. Realizar estudos, projetos e análises de interesse para a gerência/coordenação de Atenção Básica para o fortalecimento das ações de monitoramento e avaliação da SES;

g. Colaborar com a SES no apoio ao desenvolvimento de capacidade técnica nos municípios para o fortalecimento das ações de monitoramento e avaliação da Atenção Básica;

h. Desenvolver estudos operacionais com a utilização dos bancos de dados dos sistemas de informações em saúde do SUS;

i. Assessorar a SES no desenvolvimento dos Planos de Monitoramento e Avaliação da Atenção Básica nos municípios do PROESF;

j. Participar, juntamente com as SES, das atividades, oficinas e demais eventos realizados pelo DAB/Ministério da Saúde para aperfeiçoamento das ações de monitoramento e avaliação da atenção básica.

\section{Atribuições das Secretarias Estaduais de Saúde}

Tendo por referência a concepção, linhas norteadoras e macroestratégias dos Planos Estaduais, cabe às SES:

Obs.: Muitas das atribuições elaboradas foram adaptadas do documento "Relatório Final do I Seminário para Construção de Consensos", realizado pelo CONASS em Sergipe de 2003.

a. Aprofundar o debate sobre competências e responsabilidades da Atenção Básica, com incorporação das Vigilâncias;

b. Elaborar e/ou implementar instrumentos gerenciais que permitam a integração e coordenação das ações da atenção básica;

c. Priorizar a celebração do Pacto da Atenção Básica, utilizando-o como ferramenta de planejamento e gestão;

d. Elaborar e executar o Plano Estadual para o Fortalecimento das Ações de Monitoramento e Avaliação da Atenção Básica, em consonância com os direcionamentos aqui elencados;

e. Garantir pessoal do quadro técnico da SES para as ações de monitoramento e avaliação da atenção básica em quantidade compatível com o porte de estado;

f. Viabilizar técnica e politicamente estratégias para integração das ações estaduais de Monitoramento e Avaliação da Atenção Básica;

g. Contratar instituições para atuarem como "Centros Colaboradores em Avaliação da Atenção Básica", seguindo a legislação estadual vigente; 
h. Colaborar com os municípios participantes do componente I do PROESF na elaboração de estratégias para monitoramento e avaliação da atenção básica;

i. Implementar as ações de monitoramento e avaliação da atenção básica em todos os municípios do estado no que se refere a:

i.a. Acompanhamento das informações em saúde (SIM, SINASC, SINAN, SIAB e outros) e dos indicadores definidos nos diferentes pactos (Programação Pactuada Integrada da assistência e da Vigilância, da Atenção Básica), utilizando-os para análise de situação e planejamento;

i.b. Definição e implantação de instrumentos, parâmetros, metodologias de avaliação quantitativas e qualitativas que resultem em melhoria da resolubilidade da atenção;

i.c. Assessoramento técnico para formulação, aprimoramento e utilização do Pacto da Atenção Básica e SIAB como instrumentos de planejamento das ações;

i.d. Análise sistemática dos bancos de dados dos sistemas de informação em saúde utilizados na atenção básica;

\section{Referências}

1. Ministério da Saúde. Secretaria de Atenção à Saúde. Departamento de Atenção Básica. Coordenação de Acompanhamento e Avaliação Planos Estaduais para o Fortalecimento das Ações de Monitoramento e Avaliação da Atenção Básica. Diretrizes e Orientações. Disponível em: www.saude.gov.br/caadab [2003 set 18].

2. Demo, P. Complexidade e aprendizagem: a dinâmica nãolinear do conhecimento. São Paulo: Atlas; 2002.

3. Outhwaite W, Bottomore T. Dicionário do pensamento social do século XX. Rio de Janeiro: Jorge Zahar; 1996. i.e. Assessoria técnica em monitoramento e avaliação da atenção, traçando estratégias diferenciadas a partir das diferentes realidades e aperfeiçoando o uso integrado dos diversos sistemas de informação e instrumentos de planejamento do SUS;

i.f. Estudos, definição de metodologia e instrumentos para acompanhamento das Equipes Saúde da Família.

j. Contribuir com o DAB/SAS/MS na implementação das adequações do SIAB;

k. Acompanhar e avaliar a atenção básica em $100 \%$ dos municípios participantes do componente I do PROESF, focalizando os indicadores constantes na "Carta de compromisso" assinada entre município e Ministério da Saúde;

1. Apoiar o desenvolvimento de capacidade técnica dos municípios para o monitoramento e avaliação da atenção básica, construindo coletivamente as ações, metas, indicadores e instrumentos de avaliação a serem pactuados na CIB;

m. Colaborar com as instituições de pesquisa executoras dos estudos de Linha de Base nos municípios participantes do componente I do PROESF.

Recebido em 2 de setembro de 2004 